\title{
SIMULTANEOUS DESULFURIZATION AND DENITROGENATION OF LIQUID FUEL BY NICKEL MODIFIED GRANULAR ACTIVATED CARBON
}

\section{Sandeep Kumar Thaligari ${ }^{1}$, Shelaka Gupta ${ }^{1,2}$, Vimal Chandra Srivastava ${ }^{1, *}$, Basheshwer Prasad $^{1}$}

${ }^{1}$ Department of Chemical Engineering, Indian Institute of Technology Roorkee, Roorkee 247667

Uttarakhand, India

${ }^{2}$ Department of Chemical Engineering, Indian Institute of Technology Delhi, Hauz Khas, New Delhi 110016 Delhi, India

*Corresponding author. Tel.: +91-1332-285889. Fax: +91-1332-276535. E-mails: vimalcsr@yahoo.co.in (VCS), sandyouct@gmail.com (TSK), guptashelaka@gmail.com (SK), bprasad62@gmail.com (BP)

SUPPORTING INFORMATION

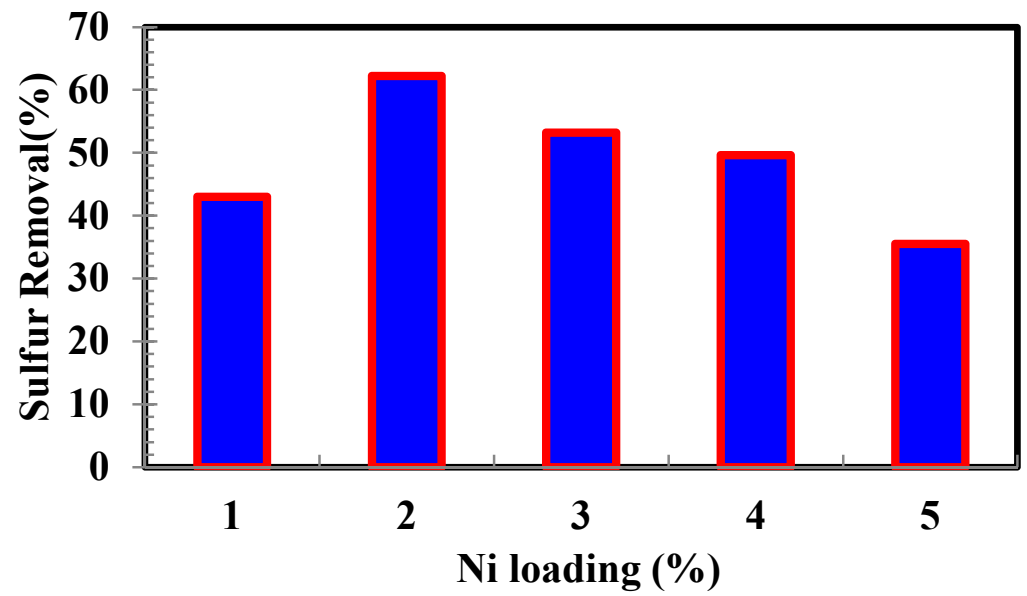

Figure S1. Variation of sulfur removal with Ni loading on GAC. $C_{0, D B T}=15.62 \mathrm{mmol} / \mathrm{l}$, $\mathbf{T}=303 \mathbf{K}, \mathbf{t}=\mathbf{9} \mathbf{h}$. 


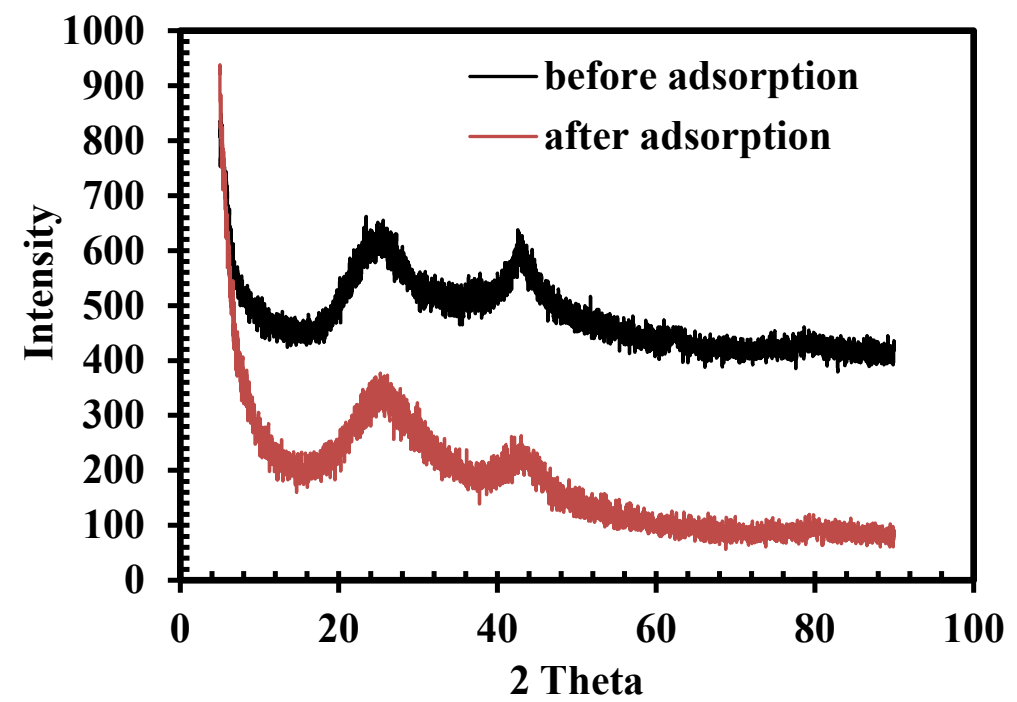

Figure S2. XRD pattern of Ni-GAC before and after adsorption of $\mathrm{N}$ and $\mathrm{S}$. 


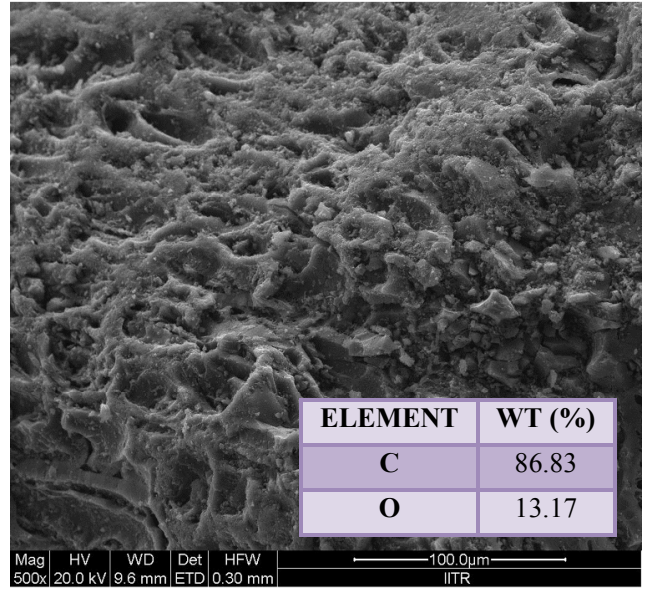

(a)

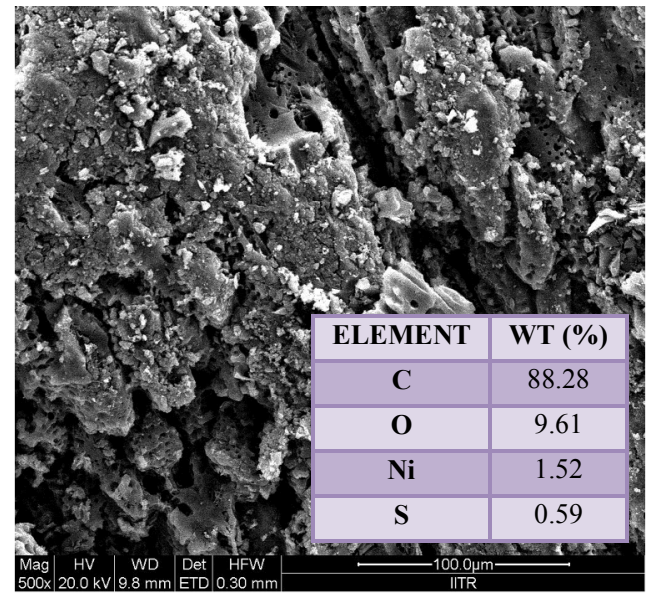

(c)

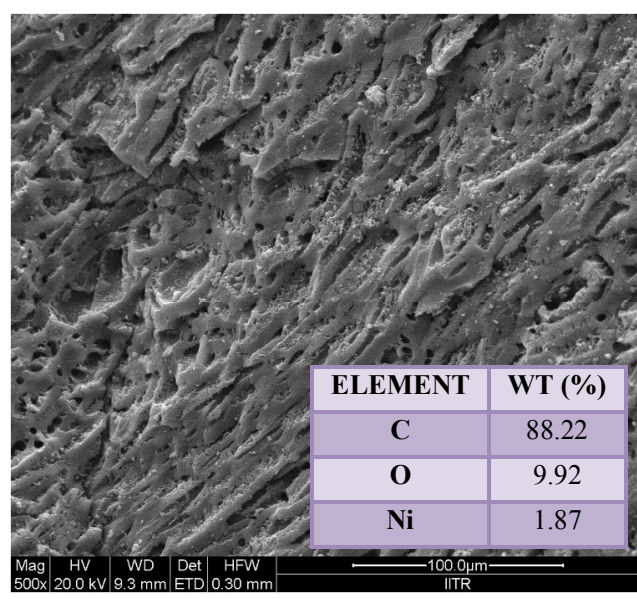

(b)

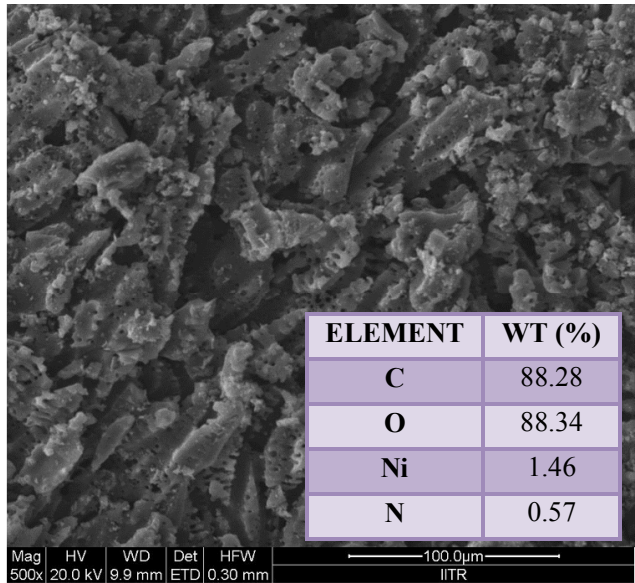

(d)

Figure S3. Fe-SEM images and EDX analysis of (a) GAC, (b) Ni-GAC, (c) Ni-GAC-S, and (d) Ni-GAC-N. 


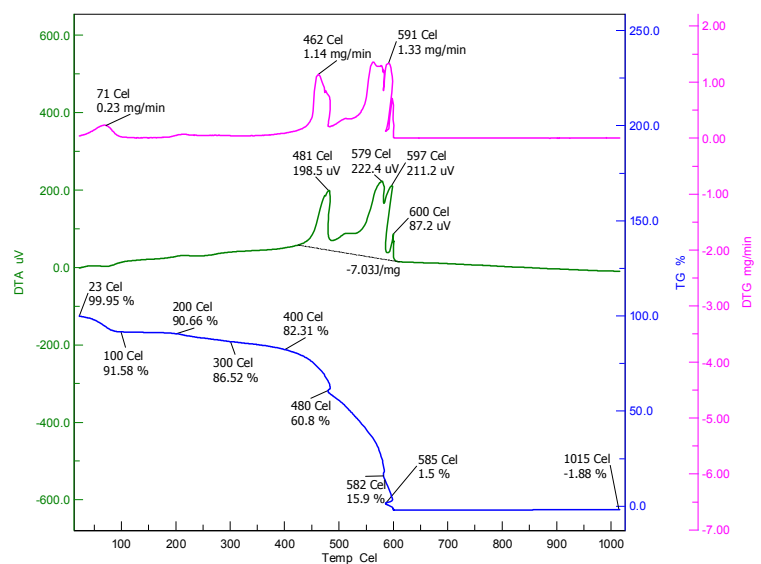

(a)

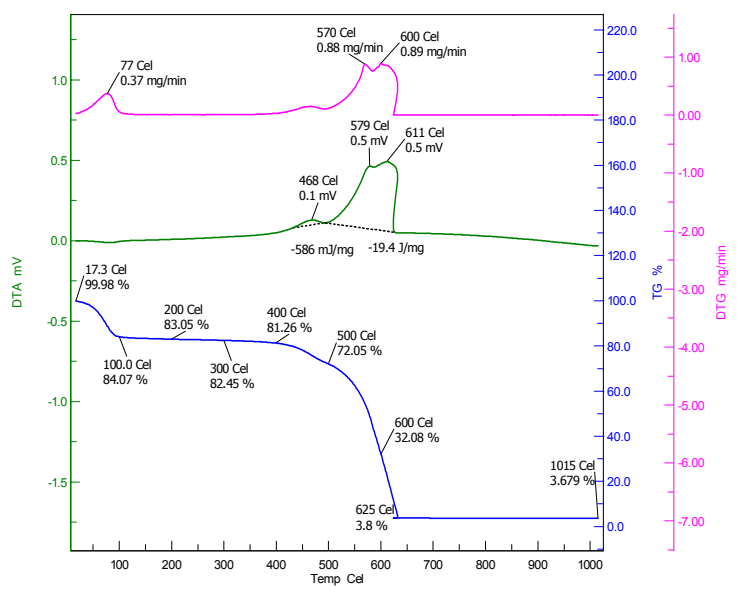

(b)

Figure S4. Differential thermal gravimetric and differential thermal analysis of Ni-GAC (a) before and (b) after adsorption. 